\title{
TUTELA Y PROMOCIÓN DE LOS DERECHOS SOCIALES Y LABORALES POR LAS DIRECTIVAS EUROPEAS SOBRE CONTRATACIÓN PÚBLICA DE CUARTA GENERACIÓN: SU INCORPORACIÓN AL ORDENAMIENTO JURÍDICO ESPAÑOL
}

\author{
PROTECTION AND PROMOTION OF SOCIAL AND LABOR RIGHTS \\ BY THE FOURTH GENERATION OF EUROPEAN DIRECTIVES ON \\ PUBLIC PROCUREMENT: ITS INCORPORATION INTO THE SPANISH \\ LEGAL SYSTEM
}

\section{Alejandro Román Márquez*}

\begin{abstract}
RESUMEN: La consagración definitiva de la contratación pública socialmente responsable por las directivas europeas de cuarta generación, así como su desarrollo y potenciación por el legislador español, plantean el reto de armonizar dos de los principios fundamentales de la Unión Europea: el libre mercado y el progreso social de los ciudadanos europeos, además de demandar una reinterpretación respecto de los parámetros clásicos del principio de eficiencia en el gasto público.
\end{abstract}

Palabras clave: Contratación pública social, contratación pública sostenible, economía social de mercado, eficiencia en el gasto público.

ABSTRACT: The definitive consecration of socially-responsible public procurement by the fourth generation of European Directives, as well as their development and empowerment by the Spanish legislator, poses the challenge of harmonizing two of the fundamental principles of the European Union: free market and progress of European citizens, in addition to demanding a reinterpretation of the classic parameters of the principle of efficiency in public spending.

Keywords: Socially-responsible public procurement, sustainable public procurement, social market economy, efficiency in public spending.

\section{INTRODUCCIÓN. LA CONTRATACIÓN PÚBLICA COMO INSTRUMENTO DE LA POLÍTICA SOCIAL DE LA UNIÓN EUROPEA}

a) Orígenes de la CONTRATACión pÚblica social en la Unión EURopea y RECEPCIÓN EN EL DERECHO ESPAÑOL

Si bien las preocupaciones inherentes al Estado social -Sozialstaat- han impregnado la política europea, incluso desde antes de la aprobación del primer Programa de Acción

\footnotetext{
* Doctor en Derecho, Universidad de Granada. Profesor del Departamento de Derecho Administrativo de la Universidad de Sevilla y miembro del Instituto Universitario de Investigación García Oviedo. Dirección postal: Calle José Saramago N²5, 6 A, CP 41013 Sevilla, España. Dirección electrónica: aroman2@us.es.
} 
Social (1974), la inclusión de principios del Estado social en el Derecho originario de la Unión Europea ha supuesto la consagración definitiva de este sistema político, social y económico a nivel comunitario. Así, el artículo 3.3 del Tratado de la Unión Europea exhorta a sus instituciones a alcanzar un desarrollo sostenible de Europa a través de un crecimiento económico equilibrado, en el marco de una economía social de mercado altamente competitiva, tendente al pleno empleo y al progreso social, en la que se combata la exclusión social y la discriminación y se fomente la justicia y la protección sociales, la igualdad entre mujeres y hombres, la solidaridad inter generacional y la protección de los derechos del niño, con el objetivo último de lograr la cohesión económica, social y territorial, y la solidaridad entre los Estados miembros. Por su parte, el artículo 9 del Tratado de Funcionamiento de la Unión Europea exige a esta que tenga en cuenta, en la definición y ejecución de sus políticas y acciones, la promoción de un nivel de empleo elevado, la garantía de una protección social adecuada, la lucha contra la exclusión social, así como un alto nivel de educación, formación y protección de la salud humana.

Durante las últimas décadas la Unión Europea ha venido reconociendo expresamente que la contratación pública puede constituir un poderoso instrumento para el logro de varios objetivos comunitarios, alcanzan y consolidan un efecto de sinergia con algunas políticas comunitarias ${ }^{1}$, como aquellas ligadas a la sostenibilidad, habida cuenta de la enorme relevancia que la contratación pública posee para la economía de la Unión -en torno a un 19\% de su PIB-. Dicha sostenibilidad ha sido afrontada desde una doble perspectiva: ambiental y social. Con relación a la segunda de ellas, la Comisión Europea fue plasmando sus puntos de vista en una serie de documentos que se remontan a finales de los años ochenta del siglo pasado y que han funcionado a modo de soft law en la materia ${ }^{2}$. También el Tribunal de Justicia de la Unión ha tenido ocasión de pronunciarse sobre estas cuestiones, conformando un acervo jurisprudencial que ha ido encontrando acomodo en las sucesivas directivas sobre contratación pública, fundamentalmente a partir de su tercera generación ${ }^{3}$. Como no podía ser de otro modo, también el Derecho interno de los Estados Miembros ha ido reproduciendo las tendencias positivizadas en el Derecho derivado, cerrando el círculo de integración entre los diferentes ordenamientos jurídicos que conviven en el espacio europeo.

La “compra pública social”, definida como aquella que integra las inquietudes sociales en los procedimientos de adjudicación de contratos públicos con el objetivo de contrarrestar las desventajas sociales y laborales de determinados colectivos en situación o riesgo

\footnotetext{
1 Comunicación de la Comisión Europea de 11 de marzo de 1998 "La contratación pública en la Unión Europea” Comisión Europea (1998) pp. 25, 28 y 29.

2 Además del documento citado en la nota al pie anterior, Comisión Europea (1989); el Libro Verde "La Contratación pública en la Unión Europea: reflexiones para el futuro” (1996); la Comunicación interpretativa de 15 de octubre de 2001 "sobre la legislación comunitaria de contratos públicos y las posibilidades de integrar aspectos sociales en dichos contratos" (COM (2001) 566 final), el Libro Verde "Fomentar un marco europeo para la responsabilidad social de las empresas" (2001, COM (2001) 366 final), o el Libro Verde "sobre la modernización de la política de contratación pública de la UE. Hacia un mercado europeo de la contratación pública más eficiente" (2011, COM (2011) 15 final). En relación a la estrategia social y ambiental europea en materia de contratación pública véase EsTORNINHO (2014) pp. 2749-2758.
}

3 Directivas 2004/17/CE y 2004/18/CE. 
de exclusión social ${ }^{4}$ y de mejorar las condiciones laborales y sociales de los ciudadanos en general, se configura como un instrumento clave para el cumplimiento de las políticas sociales de la Unión Europea, y así se manifiesta reiteradamente en los documentos, pronunciamientos jurisprudenciales y normas jurídicas que se ocupan de esta materia. Un ejemplo de la importancia que han adquirido las cuestiones sociales en el ámbito de la contratación pública es el notable hecho de que la Directiva 2014/24/UE, de 26 de febrero, sobre contratación pública y por la que se deroga la Directiva 2004/18/CE, haya incluido por primera vez entre los principios de la contratación el cumplimiento de las obligaciones sociales y laborales contenidas en el Derecho de la Unión, el Derecho nacional, los convenios colectivos y el Derecho internacional'5.

El ordenamiento jurídico español admite expresamente en su recientemente aprobada Ley 9/2017, de 8 de noviembre, de Contratos del Sector público (en adelante LCSP), la inclusión de consideraciones sociales en todas las fases de la contratación pública: diseño del objeto contractual, admisión de candidatos, adjudicación y ejecución del contrato ${ }^{6}$. En cualquier caso, resulta necesario diferenciar, dentro del conjunto de previsiones normativas -tanto europeas como nacionales- relativas a la dimensión social de los contratos públicos, entre las denominadas "cláusulas sociales conservadoras", que se limitan a exigir a los órganos de contratación que comprueben y garanticen el cumplimiento de la legislación social y laboral vigente con ocasión de la adjudicación y ejecución de un contrato, y las denominadas "cláusulas sociales innovadoras", que superan el mero cumplimiento de las obligaciones jurídicas, aumentando los estándares sociales y laborales de la contratación pública ${ }^{7}$.

b) LA DiCOTOMÍA ENTRE OBLIGATORIEDAD Y VOLUNTARIEDAD DE LA COMPRA PÚBLICA SOCIAL EN LOS ORDENAMIENTOS JURÍDICOS EUROPEO Y ESPAÑOL

Quizás la pregunta más importante que deben plantearse los operadores jurídicos en esta materia sea la referente a la voluntariedad u obligatoriedad del uso de la contratación pública socialmente responsable. A nivel comunitario, las directivas de cuarta generación ${ }^{8}$ renuncian a imponer a la contratación pública unos requisitos sociales de carácter general y obligatorio, justificando esta decisión en las "grandes diferencias existentes entre los distintos sectores y mercados" , por lo que los supuestos en los que el Derecho comunitario impone obligaciones sociales en la contratación pública son excepcionales ${ }^{10}$.

Para contestar a la cuestión planteada desde la perspectiva del Derecho interno resulta ineludible partir del artículo 1.3 LCSP, el cual dispone que en toda contratación pública deberán incorporarse criterios sociales de forma "transversal" y "preceptiva". El legislador español apuesta por un sistema obligatorio y generalizado -en todas sus fases- de contrata-

\footnotetext{
4 Incluyendo la adquisición de productos de comercio justo que contribuyan a alcanzar un verdadero desarrollo sostenible. Medina (2012) p. 218.

5 Artículo 18.2. Desde la perspectiva específicamente laboral véase MiRANDA (2016) pp. 69-91.

6 Por todos, véanse los arts. 125.1 y 122.2 .

7 ANDRÉs (2016).

8 Directivas 2014/23/UE, 2014/24/UE y 2014/25/UE.

9 Considerando $N^{\circ} 95$ de la Directiva 2014/24/UE.

10 Por ejemplo, la obligación impuesta en el artículo 42.1 párrafos cuarto y quinto de la Directiva 2014/24/UE.
} 
ción pública socialmente responsable. Sin embargo, otros preceptos, como el artículo 28.2 LCSP, parecen rebajar esta exigencia a una mera recomendación, al señalar que las entidades contratantes "valorarán la incorporación de consideraciones sociales [...] como aspectos positivos en los procedimientos de contratación pública”.

Más allá de la aparente contradicción entre estos dos preceptos, los cuales regulan aspectos generales de la contratación pública, resulta necesario examinar uno por uno los preceptos que reglamentan la incorporación de cláusulas sociales en la contratación pública para determinar, en cada caso concreto, si los legisladores europeo y español los han configurado como una obligación ineludible o, por el contrario, como una mera posibilidad a disposición de los órganos de contratación. En las páginas siguientes se dará somera cuenta de la evolución y situación actual de los variados mecanismos que conforman la compra pública socialmente responsable tanto a nivel europeo como del ordenamiento jurídico español, centrando el análisis en las fases más relevantes de la contratación pública, para finalizar con una reflexión acerca de la utilidad de estas figuras, su influencia decisiva en la reconfiguración de alguno de los principios del Derecho comunitario, como es el principio de eficiencia en el gasto público, y su encaje en el sistema de economía social de mercado ${ }^{11}$, el cual inspira todo el edificio jurídico e institucional de la Unión Europea.

\section{EL USO DE CLÁUSULAS SOCIALES PARA LA DETERMINACIÓN DE LA MEJOR OFERTA}

\section{a) LOS PRONUNCIAMIENTOS JURISPRUDENCIALES PIONEROS EN LA MATERIA}

Como recuerda GosálBeZ ${ }^{12}$, la inclusión de cláusulas sociales entre los criterios establecidos por el órgano de contratación para determinar cuál de las ofertas presentadas por los licitadores debe considerarse como económicamente más ventajosa ha sido la vía más utilizada por las administraciones públicas para la consecución de los objetivos sociales a través de la contratación pública. Al mismo tiempo, es la práctica administrativa que más controversias ha suscitado tanto a nivel jurisprudencial como doctrinal ${ }^{13}$, y que mayor evolución ha experimentado a lo largo del tiempo. Aymerich y Ferreira ${ }^{14}$ hacen notar la diferente posición que ha tenido la jurisprudencia europea en relación a las cláusulas sociales como criterios de adjudicación del contrato en contraste, por ejemplo, con su admisión como condiciones especiales de ejecución. Mientras que la jurisprudencia europea se mostró inicialmente reticente -cuando no frontalmente opuesta- a la admisión de criterios sociales en la fase de selección de las ofertas, no ocurrió así en relación a la fase de ejecución de los contratos, en los que se admitió desde un principio sin mayores problemas. Recuérdese cómo la sentencia del Tribunal de Justicia de las Comunidades Europeas

\footnotetext{
11 Sobre este concepto véase, entre otros, MÜller-ArmaCK (1962) pp. 173-221; o Sols et al. (2009) pp. 79-102. Recientemente, Comisión Europea (2017).

12 Gosálbez (2003) p. 46.

13 En contra del uso de cláusulas sociales en la fase de adjudicación de los contratos públicos puede citarse, entre otros, a SANTías (2001) p. 78. Igualmente en contra, en cualquiera de las fases del contrato, ArRowsmitH (2002) pp. 11 y ss. A favor, entre otros, Aymerich y Ferreira (2014) p. 41.

14 Aymerich y Ferreira (2014) p. 41.
} 
de 20 de septiembre de 1988 (Gebroeders Beentjes vs Reino de los Países Bajos, asunto 31/87) rechazó en un principio que las consideraciones sociales pudiesen ser usadas como criterios de selección de la oferta económicamente más ventajosa precisamente por carecer de contenido económico y, por lo tanto, de virtualidad para determinar cuál era la mejor oferta desde una perspectiva exclusivamente económica (la única a la que debía atenderse en aquel momento para la adjudicación del contrato), pero no puso ningún reparo a su utilización como condición especial de ejecución de los contratos.

En el mismo sentido, la Comisión Europea, en su Comunicación interpretativa de 15 de octubre de 2001, sobre la legislación comunitaria de contratos públicos y las posibilidades de integrar aspectos sociales en dichos contratos ${ }^{15}$, negó a las cláusulas sociales capacidad para dilucidar la oferta económicamente más ventajosa, al considerar que todos los criterios de adjudicación elegidos debían comportar una ventaja económica "directa" al órgano de contratación -lo cual no hacían, a su entender, los criterios sociales-, y sin que bastase con que cada uno de ellos pudiesen medirse en términos económicos.

La sentencia del Tribunal de Justicia de las Comunidades Europeas de 26 de diciembre de 2000 (Comisión vs Francia Nord-Pas-de-Calais, asunto C-225/98) sería el primer pronunciamiento jurisprudencial comunitario que puso en cuestión la citada opinión de la Comisión Europea, pues admite que los órganos de contratación utilicen como criterio de adjudicación una cuestión relacionada con la lucha contra el desempleo, si bien respetando en todo caso los principios fundamentales del Derecho comunitario y, en concreto, los principios de no discriminación ${ }^{16}$ y de libre prestación de servicios, así como las normas relativas al procedimiento de contratación y publicidad de las licitaciones. Sin embargo, el Gobierno francés calificó el referido criterio como uno de adjudicación "adicional" y no “[...] principal, como los recogidos en el artículo 29 de la Directiva 71/305, cuyo objeto es hacer posible la determinación de la oferta más ventajosa, sino un criterio accesorio no determinante", por lo que únicamente podría ser utilizado como criterio de desempate entre ofertas. Esta restrictiva posibilidad sería la única admitida por la Comisión Europea en la referida Comunicación interpretativa de $2001^{17}$.

\section{b) La Sentencia del Tribunal de Justicia “Concordia Bus Finland” y las} DIRECTIVAS EUROPEAS SOBRE CONTRATOS PÚBLICOS DE TERCERA GENERACIÓN

La sentencia del Tribunal de Justicia de las Comunidades Europeas de 17 de septiembre de 2002 (Concordia Bus Finland Oy Ab vs Helsingin Kaupunki et al., asunto C-513/99) va a constituir un hito en la materia, al separarse de la mencionada opinión de la Comisión Europea relativa a la necesidad de que todos los criterios de adjudicación elegidos por los órganos de contratación comportasen necesariamente una ventaja económica "directa" al órgano de contratación, y también por terminar con la limitación del uso de

15 Comisión Europea (2001), pp. 14 y 15.

16 Así lo recuerda, en relación con los criterios de adjudicación, la sentencia del Tribunal de Justicia de las Comunidades Europeas de 27 de octubre de 2005 (Contse SA, Vivisol Srl y Oxigen Salud SA vs Instituto Nacional de Gestión Sanitaria (Ingesa), asunto C-234/03).

17 Pp. 14 y 15. 
criterios de adjudicación a los supuestos de desempate entre ofertas. El Tribunal de Justicia entiende que del ordenamiento jurídico comunitario -entonces vigente- no se desprende que todos los criterios de adjudicación deban tener necesariamente naturaleza económica, pues las propias directivas sobre contratación pública de segunda generación ${ }^{18}$ admitían un criterio de naturaleza no económica: las características estéticas de la oferta ${ }^{19}$. En este sentido, señala el Tribunal de Justicia que, "[e]n efecto, no cabe excluir que factores que no son puramente económicos puedan afectar al valor de una oferta para dicha entidad adjudicadora" ${ }^{20}$, lo que da así entrada a la posibilidad de que criterios no económicos -esto es, no "cuantitativos" sino "cualitativos", como las cláusulas sociales- formen parte de los criterios de selección de la oferta económicamente más ventajosa. GosálBEZ sintetiza este cambio de paradigma señalando que, para el Tribunal de Justicia, "[u]na cosa es que la oferta seleccionada deba generar beneficios económicos para la entidad pública contratante, y otra muy distinta es que todos y cada uno de los criterios que han de valorarse para determinar cuál es esa mejor oferta, deban además constituir ventajas económicas para dicho ente público [...]. Precisamente porque ese criterio de adjudicación no reside únicamente en el precio, esto es, en el valor estrictamente económico de las prestaciones contractuales requeridas por la Administración, es porque no es necesario cuantificar económicamente todos los elementos o criterios que lo integran, y tampoco es preciso que todos ellos impliquen ventajas para la entidad contratante; las ventajas exigidas por el ordenamiento comunitario se refieren a la oferta global, en su conjunto, no a todos los elementos que la componen" ${ }^{21}$. A partir de este momento las consideraciones de naturaleza social y laboral podrán constituir, por consiguiente, auténticos criterios de adjudicación del contrato, en un plano de igualdad con el resto de criterios de selección de la oferta, y no como meros criterios "adicionales" de desempate ${ }^{22}$.

Las directivas sobre contratación pública de tercera generación, y en particular la Directiva 2004/18/CE, de 31 de marzo, sobre coordinación de los procedimientos de adjudicación de los contratos públicos de obras, de suministro y de servicios, positivizan esta jurisprudencia europea. La Directiva 2004/18/CE admite expresamente, en su Considerando $\mathrm{N}^{\circ} 1$, el uso de cláusulas sociales como criterios de adjudicación de los contratos, si bien lo condicionan a que "[...] dichos criterios estén vinculados al objeto del contrato, no otorguen al poder adjudicador una libertad de elección ilimitada, estén expresamente mencionados y se atengan a los principios fundamentales [...]" de la contratación pública en el marco del ordenamiento comunitario. Esta posibilidad se reitera en su Considerando $N^{\circ} 46 \$ 4$, admitiéndose que, siempre que se respete el principio de igualdad de trato -en el sentido de posibilitar una comparación y evaluación objetiva de las ofertas-, será posible que los órganos de contratación utilicen criterios de adjudicación no solamente económi-

${ }_{18}$ Directivas 92/50/CEE, 93/36/CEE y 93/37/CEE.

19 Artículo 36.1 letra a) de la Directiva 92/50/CEE.

20 Apartado $\mathrm{N}^{\circ} 55$.

21 Gosálbez (2003) p. 64 y 65.

22 Este nuevo parecer sobre las cláusulas sociales como criterios de adjudicación fue recogido rápidamente por las Juntas Consultivas de Contratación Administrativa españolas, como hizo, por ejemplo, la valenciana en su Dictamen $\mathrm{N}^{\circ} 1 / 2003$, de 21 de marzo. 
cos, sino también cualitativos, como son los criterios sociales. En tal sentido, el poder adjudicador podrá regirse por criterios destinados a la satisfacción de exigencias sociales que, en particular, respondan a las necesidades de aquellos sectores de la población "especialmente desfavorecidos”. A pesar de esta previsión expresa, la Directiva 2004/18/CE no hizo mención alguna a los criterios sociales en el precepto dedicado a los criterios de adjudicación ${ }^{23}$, cosa que sí hace con otros criterios cualitativos relativos a la sostenibilidad de las ofertas, como las características medioambientales de la prestación ${ }^{24}$. El carácter meramente ejemplificativo del listado de criterios de adjudicación aceptados por la Directiva, junto con las previsiones expresas de la jurisprudencia comunitaria y de los citados considerandos, despejarían las dudas sobre la admisibilidad de las consideraciones sociales como criterios de adjudicación de los contratos públicos.

c) LAS DIRECTIVAS EUROPEAS SOBRE CONTRATOS PÚBLICOS DE CUARTA GENERACIÓN Y LA Ley 9/2017, de 8 de nOVIEMbre, de Contratos del Sector público

Las actuales directivas de contratos de cuarta generación continúan la línea de integración progresiva de los criterios sociales de adjudicación en la normalidad de la actuación administrativa. Así, la Directiva 2014/24/UE señala en sus Considerandos No 97 y $\mathrm{N}^{\circ} 99$ que "[...] a fin de lograr una mayor integración de las consideraciones sociales [...], los poderes adjudicadores deben estar autorizados a adoptar criterios de adjudicación [...] en lo que se refiere a obras, suministros o servicios que vayan a facilitarse en el marco de un contrato público en cualquiera de los aspectos y en cualquier fase de sus ciclos de vida [...]. Las medidas destinadas a proteger la salud del personal que participa en el proceso de producción, a favorecer la integración social de las personas desfavorecidas o de los miembros de grupos vulnerables entre las personas encargadas de ejecutar el contrato o a ofrecer formación para adquirir las competencias necesarias para el contrato de que se trate podrán estar también sujetas a criterios de adjudicación [...] siempre que se refieran a las obras, suministros o servicios que hayan de facilitarse con arreglo al contrato en cuestión”. En el listado ejemplificativo de criterios de adjudicación facilitados por la propia Directiva figuran el empleo de desempleados de larga duración o las medidas en materia de formación para desempleados o jóvenes durante la ejecución del contrato ${ }^{25}$.

En las directivas vigentes el contrato sigue debiendo adjudicarse a la "oferta económicamente más ventajosa" 26 . Sin embargo, ahora esta oferta económicamente más ventajosa puede determinarse con arreglo a uno de los siguientes elementos, en los que pueden incluirse consideraciones de naturaleza social ${ }^{27}$ : a) la relación coste-eficacia, como el cálculo del coste del ciclo de vida, y b) la relación calidad-precio, que se efectuará en función de

23 Véase su artículo 53.

24 Lo mismo que ocurre en el artículo 55 de la Directiva 2004/17/CE.

25 Lo aquí señalado se hace igualmente extensivo, de forma expresa, a las condiciones de ejecución del contrato, unificándose a este respecto el tratamiento que hace la Directiva 2014/24/UE de las cláusulas sociales en las fases de adjudicación y ejecución de los contratos públicos.

26 Véase el art. 67.1 de la Directiva 2014/24/UE.

27 Artículo 67.2 de la Directiva 2014/24/UE. En este sentido, el Tribunal de Justicia de la Unión Europea admitió la posibilidad de adjudicar un contrato a la oferta más ventajosa, aunque su coste final pudiese ser más 
criterios que incluyan aspectos cualitativos, medioambientales y/o sociales vinculados al objeto del contrato en cuestión.

Por el contrario, el legislador español va a prescindir en la nueva Ley de Contratos del Sector Público del concepto tradicional de la oferta económicamente más ventajosa, si bien establece, al igual que hace la Directiva 2014/24/UE, la obligación de adjudicar el contrato a la oferta que presente una mejor relación calidad-precio ${ }^{28}$. Excepcionalmente, y previa justificación en el expediente, el órgano de contratación podrá también adjudicar el contrato a aquélla oferta que presente una mejor relación coste-eficacia, sobre la base del precio o del coste, como el cálculo del coste del ciclo de vida ${ }^{29}$. En el primer supuesto, la mejor relación calidad-precio se evalúa con arreglo a criterios económicos y cualitativos, dentro de los cuales el artículo 145.2 LCSP incluye expresamente los aspectos sociales -como criterios cualitativos-, y aporta un listado abierto de características sociales del contrato que pueden ser utilizadas por el órgano de contratación como criterios de adjudicación ${ }^{30}$. En tal sentido, el legislador español reconoce expresamente que "por primera vez" se establece la obligación de que los órganos de contratación velen porque el diseño de los criterios de adjudicación permita obtener obras, suministros y servicios de gran calidad "[...] concretamente mediante la inclusión de aspectos cualitativos, medioambientales, sociales e innovadores vinculados al objeto del contrato" ${ }^{31}$. Si bien los criterios cualitativos deben ir siempre acompañados de un criterio relacionado con los costes ${ }^{32}$, este puede ser el precio pero también un planteamiento basado en la rentabilidad, como el cálculo del coste del ciclo de vida, el cual, como se verá a continuación, también puede tener en cuenta circunstancias de naturaleza social.

De otra parte, en aquellos supuestos en los que el órgano de contratación opte por adjudicar el contrato con base en la mejor relación coste-eficacia, cobrará una enorme relevancia el cálculo del coste del ciclo de vida ${ }^{33}$. El concepto de "ciclo de vida" hace referencia a todos los procesos y operaciones relativos a una obra, suministro y servicio, incluyendo las etapas previas a su nacimiento, necesarias para su concepción, y las posteriores a su finalización, destinadas a su completa eliminación o reutilización ${ }^{34}$. La noción de coste del

elevado (sentencia de 18 de octubre de 2001, SIAC Construction Ltd vs County Council of the County of Mayo, asunto C-19/00). RAZQUin y VázQuez (2017) p. 186.

28 Artículo 145.1 LCSP.

29 Artículo 145.1 párrafo segundo LCSP.

30 El artículo 145.2.1 ${ }^{\circ}$ párrafo tercero LCSP admite expresamente, entre otros criterios de adjudicación del contrato, el fomento de la integración social de las personas con discapacidad, desfavorecidas o miembros de grupos vulnerables, los planes de igualdad de género que se apliquen en la ejecución del contrato, el fomento de la contratación femenina, la conciliación de la vida laboral, personal y familiar; la mejora de las condiciones laborales y salariales, la estabilidad en el empleo, la contratación de un mayor número de personas para la ejecución del contrato, la formación y la protección de la salud y la seguridad en el trabajo, la aplicación de criterios éticos y de responsabilidad social a la prestación contractual, o los criterios referidos al suministro o a la utilización de productos basados en un comercio equitativo durante la ejecución del contrato.

31 Exposición de Motivos, apartado II $₫$ segundo LCSP.

32 Artículo 145.2 LCSP.

33 Artículo 148 LCSP.

34 Artículos 2.1.20 de la Directiva 2014/24/UE y 148.1 LCSP. 
ciclo de vida incluye todos los costes a lo largo del ciclo de vida de las obras, suministros y servicios ${ }^{35}$, entre los que figuran los denominados costes "internos", como los vinculados con la investigación, desarrollo, producción, transporte, uso, mantenimiento y eliminación; y "externos", en este caso vinculados con factores medioambientales, como la contaminación generada por la extracción de las materias primas utilizadas en el producto o causadas por el propio producto o por su fabricación, con el requisito de que puedan ser cuantificados en términos monetarios y ser objeto de seguimiento. Tanto la Directiva 2014/24 como la LCSP incluyen expresamente ${ }^{36}$, dentro de los costes internos del ciclo de vida, los referidos a suministros o utilización de productos basados en un comercio equitativo, y pueden referirse, por ejemplo, al hecho de que el producto en cuestión provenga del comercio justo, incluyéndose en este caso el requisito de pagar un precio mínimo y una prima a los productores. El método para el cálculo del coste del ciclo de vida podrá ser elaborado por cada órgano de contratación cumpliendo los requisitos establecidos en el artículo 148.3 LCSP, a menos que una norma de la Unión Europea haga obligatorio un método común a escala comunitaria $^{37}$. El legislador español dispone, finalmente, que los órganos de contratación calculen los costes a los que se refieren los apartados primero y segundo del artículo 145 -en los que se ubican los criterios cualitativos de naturaleza social-y atiendan, preferentemente, al coste del ciclo de vida ${ }^{38}$, por lo que aquéllos deberán justificar suficientemente la elección de otro método para su cálculo.

El legislador español termina con la preponderancia concedida tradicionalmente al precio más bajo en aquellos casos en los que el órgano de contratación decidiese utilizar únicamente un criterio de adjudicación, tal y como sucedía en la regulación precedente ${ }^{39}$. Ahora, cuando solamente se utilice un criterio de adjudicación, este deberá estar relacionado necesariamente con los costes, de la misma forma que se acaba de señalar: bien eligiendo el precio más bajo, bien refiriéndose a un criterio basado en la rentabilidad, como el coste del ciclo de vida ${ }^{40}$, lo que habilita, en última instancia, a que el órgano de contratación pueda optar por un único criterio de adjudicación y que este sea de naturaleza social -y no, como sucedía hasta la entrada en vigor de la LCSP, necesariamente el precio más bajo-. Además, para evitar que el órgano de contratación elija como criterio único de adjudicación al precio más bajo, el legislador español exige ahora que en determinados supuestos resulte necesario la aplicación de más de un criterio de adjudicación, como sucede en los contratos de prestación de servicios sociales, siempre que fomenten la integración social de las personas desfavorecidas o miembros de grupos vulnerables entre las personas que participen en la ejecución del contrato, promuevan el empleo de personas con dificultades particulares de inserción en el mercado laboral, se trate de contratos de servicios sociales, sanitarios o asis-

\footnotetext{
35 Considerando No 96 y artículos 68 de la Directiva 2014/24/UE y 148.2 LCSP.

36 Considerando N 97 de la Directiva 2014/24/UE y Exposición de Motivos, apartado V $\$$ tercero y quinto LCSP.

37 Artículo 148.2 LCSP.

38 Artículo 148.4 LCSP.

39 Artículo 150.1 párrafo segundo del Real Decreto Legislativo 3/2011. El Tribunal de Justicia ya mostró su oposición a la utilización generalizada y abstracta del criterio del precio como criterio único en su sentencia de 7 de octubre de 2004 (Sintesi SpA vs Autorità per la Vigilanza sui Lavori Pubblici, asunto C-247/02).

40 Artículo 146.1 LCSP.
} 
tenciales previstos en su Disposición adicional cuadragésimo octava de esta ley (contratos reservados), de servicios intensivos en mano de obra o de seguridad privada. En todos estos casos "el precio no podrá ser el único factor determinante de la adjudicación" ${ }^{41}$. El legislador español sigue aquí la idea de que "[l]a relación calidad-precio es muy importante cuando se gasta dinero público, pero el precio más bajo no siempre garantiza el mejor valor”².

\section{LAS CONDICIONES ESPECIALES DE EJECUCIÓN DE LOS CONTRATOS DE NATURALEZA SOCIAL}

Como se ha señalado anteriormente, la admisión de condiciones especiales de ejecución de naturaleza social fue admitida por la sentencia del Tribunal de Justicia de las Comunidades Europeas de 20 de septiembre de 1988 -Beentjes-, la cual consideró compatible con el Derecho comunitario la condición impuesta al adjudicatario del contrato de emplear a trabajadores en paro prolongado. La Directiva 93/37/CEE, de 14 de junio, sobre coordinación de los procedimientos de adjudicación de los contratos públicos de obras, recogió tal posibilidad, si bien restringida a las condiciones de trabajo de los encargados de ejecutar las prestaciones contratadas, en este caso relativas a un contrato de obras ${ }^{43}$. Posteriormente, las directivas sobre contratación pública de tercera generación generalizaron la posibilidad de incluir condiciones especiales de ejecución "de tipo social” en todos los contratos regulados en ese momento por el Derecho comunitario (obras, servicios y suministros), con el objetivo manifiesto de favorecer la formación profesional en el lugar de trabajo, el empleo de personas que tuviesen especiales dificultades de inserción o combatir el paro. Además, aportaron un listado ejemplificativo de condiciones de ejecución admisibles tales como la contratación de desempleados de larga duración, la organización de acciones de formación para desempleados o jóvenes, el respeto "en lo sustancial" de las disposiciones de los convenios fundamentales de la Organización Internacional del Trabajo (OIT) -en el supuesto de que estos no se hubieran aplicado en el Derecho nacional- o la contratación de un número de personas discapacitadas superior al exigido por el Derecho interno ${ }^{44}$.

A pesar de su reconocimiento positivo, la jurisprudencia comunitaria posterior a Beentjes ha mostrado, sin embargo, algunas vacilaciones y retrocesos a la hora de aceptar las condiciones sociales de ejecución de los contratos públicos en un proceso, por tanto, no puede calificarse de lineal y pacífico. El ejemplo paradigmático de la marcha atrás del Tribunal de Justicia sería la sentencia de 3 de abril de 2008 (Dirk Rüffert vs Land Niedersachsen, asunto C-346/06). En esta se enjuicia, en el marco de una cuestión prejudicial, la compatibilidad con el Derecho comunitario de un norma aprobada por el Land de Baja

\footnotetext{
${ }^{41}$ Artículo 145.3 letra g) párrafo segundo LCSP. El peso atribuido a cada uno de estos criterios de adjudicación será determinado libremente por el órgano de contratación, si bien respetando en todo caso el principio de proporcionalidad. RAZQUin y VÁzQUez (2017) p. 185.

42 VÁzQuez (2017).

43 Véase su artículo 23.1.

44 Considerandos $N^{\circ} 33,34$ y 44, y artículo 26 de la Directiva 2004/18/CE; y Considerandos N³4 y 44, y artículo 38 de la Directiva 2004/17/CE.
} 
Sajonia ${ }^{45}$ que exigía que ciertos contratos solo podían adjudicarse a empresas que, en la licitación, se comprometiesen por escrito a pagar a sus trabajadores, en concepto de contraprestación por la ejecución de la prestación contractual, como mínimo, la retribución establecida en el convenio colectivo aplicable en el lugar de dicha ejecución. En el procedimiento de licitación que dio origen a la citada cuestión prejudicial, la empresa adjudicataria -alemana- subcontrató la ejecución del contrato con una empresa polaca. El contrato consistía en la construcción del centro penitenciario de Göttingen-Rosdorf, en territorio alemán, y hasta allí desplazó la empresa polaca a sus trabajadores, a los que se les pagó por debajo de lo establecido en el convenio colectivo alemán. El Tribunal de Justicia pondera, por un lado, el principio de libre prestación de servicios consagrado en el Derecho originario de la Unión y, por otro, la protección social de los trabajadores, inclinándose en este caso por el primero, en el entendimiento de que aplicar las condiciones laborales del lugar de ejecución del contrato a los prestadores de servicios establecidos en otro Estado miembro -en el que los salarios mínimos pueden ser inferiores- constituye "[...] una carga económica adicional que puede impedir, obstaculizar o hacer menos interesante la ejecución de sus prestaciones en el Estado miembro de acogida [...]", lo que, en definitiva, constituye una restricción injustificada del principio de libre prestación de servicios ${ }^{46}$.

Frente a esta sentencia, desconocedora del Derecho positivo vigente en esos momen$\operatorname{tos}^{47}$, reaccionaría el Parlamento Europeo en su Resolución Legislativa de 22 de octubre de 2008, sobre los retos a los convenios colectivos en la Unión Europea. Este consideró que un pronunciamiento de tal naturaleza ${ }^{48}$ hacía necesario "[...] aclarar que las libertades económicas establecidas en los Tratados deberían interpretarse de manera que no menoscaben el ejercicio de los derechos sociales fundamentales reconocidos en los Estados miembros y por el Derecho comunitario, incluido el derecho a negociar, celebrar y aplicar convenios colectivos y a emprender acciones colectivas, y que no menoscaben la autonomía de los interlocutores sociales en el ejercicio de estos derechos fundamentales en defensa de intereses sociales y de la protección de los trabajadores” ${ }^{39}$. Partiendo de esta premisa, el Parlamento Europeo mantendrá que la libre prestación de servicios no está por encima de los derechos fundamentales establecidos en la Carta de los Derechos Fundamentales de la Unión Euro-

45 Concretamente, el artículo 3.1 (“Obligación de cumplir los convenios colectivos”) de la Ley del Land de Baja Sajonia sobre contratación pública (Landesvergabegesetz).

46 Apartado 37.

47 Pues la propia Directiva 2004/18/CE señalaba (Considerando $\mathrm{N}^{\circ} 34$ ) que, para las situaciones transfronterizas, en las que los trabajadores de un Estado miembro prestan sus servicios en otros Estados miembros con motivo de la ejecución de un contrato público, la Directiva 96/71/CE enunciaba las condiciones mínimas que habían de respetarse en el país de acogida en relación con dichos trabajadores desplazados, pero no las máximas, por lo que tales condiciones podían elevarse por voluntad de los poderes adjudicadores. Esta interpretación fue acogida por la Directiva 2014/24/UE en sus Considerandos N 37 y 98. Sobre esta cuestión véase GALLEGO (2011) pp. 64-69.

48 Junto con otros en idéntica dirección, como las sentencias del Tribunal de Justicia de las Comunidades Europeas de 11 de diciembre de 2007 (International Transport Workers' Federation et al. vs Viking Line ABP et al., asunto C-438/05) o de 18 de diciembre de 2007 (Laval un Partneri Ltd. vs Svenska Byggnadsarbetareförbundet et al., asunto C-341/05).

49 2008/2085 [INI], DOUE de 21 de enero de 2010, 210/C 15E/10, p. 50 (p. 6, apartado N 5). 
pea y, en particular, del derecho de los sindicatos a la negociación y acción colectivas. Este derecho fundamental sería ratificado posteriormente, como advierte MEDINA ${ }^{50}$, por el Tratado de Lisboa, el cual entró en vigor el 1 de diciembre de 2009, por lo que a partir de este momento habrían de tenerse en cuenta las disposiciones de Derecho social originario que afectan al marco de libertades económicas en virtud de la cláusula transversal de protección social del artículo 9 TFUE y de la previsión del artículo 3.3 TUE.

La Directiva 2014/24/UE acoge expresamente la posibilidad de incluir determinadas condiciones especiales de ejecución de los contratos "[...] a fin de lograr una mayor integración de las condiciones sociales [...] en los procedimientos de contratación”, y amplía, además, el listado ejemplificativo de condiciones de ejecución de carácter social previsto en la Directiva 2004/18/CE a aquellas medidas que fomenten la igualdad entre mujeres y hombres en el trabajo, así como la mayor participación de la mujer en el mercado laboral y la conciliación del trabajo y la vida familiar ${ }^{51}$. Para poder incluir tales condiciones de ejecución la Directiva 2014/24/UE reitera los requisitos exigidos hasta el momento por la jurisprudencia y el Derecho comunitario precedente: vinculación con la prestación objeto del contrato, inclusión en la convocatoria de licitación o en los pliegos contractuales, y aplicación no discriminatoria respecto de los operadores económicos de otros Estados miembros ${ }^{52}$. Tal vinculación con el objeto del contrato justifica la prohibición relativa a que las condiciones de ejecución puedan estar referidas a circunstancias de la política general de una empresa, pues "[e]l propósito de las condiciones de ejecución de un contrato es establecer requisitos específicos en relación con dicha ejecución" ${ }^{53}$ y no con otras circunstancias sociales o laborales de la organización empresarial no relacionadas directamente con la ejecución de la prestación contratada (por ejemplo, circunstancias que afectan a trabajadores que no participan en la ejecución ${ }^{54}$ o a productos no incluidos en el contrato). En este sentido, debe tenerse presente que la vinculación entre las condiciones de ejecución del contrato y su objeto tiene una naturaleza y finalidad propia, diferente a la de otras cláusulas sociales que puedan afectar al contrato. Así lo señala el Tribunal Administrativo de Contratación Pública de la Comunidad de Madrid al analizar la finalidad de estas cláusulas por contraposición con la propia de los criterios de adjudicación, y advierte a este respecto que "[...] en el caso de que nos hallemos ante un criterio de adjudicación el parámetro de su vinculación al objeto del contrato debe necesariamente examinarse a la luz de la función específica de los criterios de valoración distintos del precio, cual es añadir calidad al producto o servicio por encima del mínimo exigido [...]. Esto no obstante, cuando hablamos de condiciones de ejecución del contrato no se trata de añadir calidad, por lo que no se trata de acreditar que la prestación será mejor cualitativamente hablando, sino que tiene por objeto garantizar

\footnotetext{
50 Medina (2012) p. 223.

51 Considerando $\mathrm{N}^{\circ} 98$.

52 Considerando $\mathrm{N}^{\circ} 97$ y artículo 70 .

53 Considerando $\mathrm{N}^{\circ} 104$.

54 Así, por ejemplo, no se podría exigir como condición especial de ejecución que la empresa contratista garantice un salario mínimo a todo su personal, sino únicamente a aquellos trabajadores que desempeñen las labores objeto del contrato. Resolución $N^{\circ}$ 196/2017, de 5 de julio, del Tribunal Administrativo de Contratación Pública de la Comunidad de Madrid, p. 15.
} 
que las prestaciones objeto del contrato se ejecutarán en la forma requerida por el órgano de contratación. Se trata por tanto de acreditar las posibles afecciones a la ejecución contractual, que por su naturaleza futura necesariamente son inciertas aunque sean posibles" 55 .

El Tribunal de Justicia de la Unión Europea ha confirmado finalmente la admisibilidad general, con los requisitos reproducidos, de las condiciones sociales de ejecución de los contratos públicos contenida en la Directiva 2014/24/UE. La sentencia de 17 de noviembre de 2015 (RegioPost GmbH \& Co. KG vs Stadt Landau in der Pfalz, asunto C-115/14) se aparta definitivamente de la doctrina fijada en la sentencia Rüffert al declarar que resulta compatible con el Derecho comunitario la normativa de un Estado miembro que obliga a los licitadores a comprometerse, en su oferta, a pagar al personal que ejecuta las prestaciones contractuales un salario mínimo fijado por dicha normativa ${ }^{56}$.

La LCSP habilita igualmente y con carácter general a los órganos de contratación para imponer a los contratistas $-y$ subcontratistas ${ }^{57}$ - condiciones especiales de ejecución de naturaleza social, aportando un listado abierto de consideraciones de tipo social o relativas al empleo que pueden ser utilizadas por aquéllos ${ }^{58}$. Pero la LCSP va, incluso, un paso más allá de lo establecido por la Directiva 2014/24/UE, pues obliga a los órganos de contratación a establecer en la documentación contractual al menos una de las condiciones especiales de ejecución previstas en su artículo 202.2, esto es, condiciones de ejecución innovadoras, medioambientales o sociales 59 . Sigue pues, a tenor de esta previsión, sin ser obligatoria la inclusión en los contratos públicos de condiciones de ejecución de carácter social, pues el órgano de contratación puede decantarse por condiciones de ejecución innovadoras o medioambientales para cumplir con la citada obligación en detrimento de aquéllas. El legislador español impone, pues, unas condiciones mínimas de ejecución sostenible o innovadora de los contratos públicos, pero sin establecer una preferencia a favor de ninguna de ellas.

La LCSP sí que prevé, no obstante, ciertas condiciones especiales de ejecución obligatorias para el contratista, el cual debe cumplir en todo caso con independencia de que hayan sido acordadas o no expresamente por el órgano de contratación. La primera de ellas se encuentra recogida en el artículo 122.2 LCSP, relativo al contenido de los pliegos de cláusulas administrativas particulares, que incluye, como parte irrenunciable de este, "[...] la obligación de adjudicatario de cumplir las condiciones salariales de los trabajadores conforme al Convenio Colectivo sectorial de aplicación”. En el mismo sentido, el artículo 35.1 letra n LCSP exige que en el contenido mínimo de todos los contratos públicos figure necesariamente "[1]a obligación de la empresa contratista de cumplir durante todo el perio-

\footnotetext{
55 Resolución N 196/2017, de 5 de julio, del Tribunal Administrativo de Contratación Pública de la Comunidad de Madrid, p. 11.

56 Apartado 53. En sentido contrario, no atenta contra el Derecho comunitario la exclusión de aquellos licitadores que se nieguen a comprometerse por escrito al pago de tales salarios (apartado 88). Sobre esta sentencia véase, entre otros, Romeo (2017) pp. 415-416.

57 Artículo 202.4 LCSP.

58 Artículo 202.2 LCSP. Entre otras, contratar un número de personas con discapacidad superior al que exige la legislación nacional, garantizar el cumplimiento de los convenios colectivos sectoriales y territoriales aplicables, fomentar la igualdad entre hombres y mujeres, o garantizar el respeto a los derechos laborales básicos a lo largo de la cadena de producción reconocidos en las normas fundamentales de la OIT.

59 Artículo 202.1 párrafo segundo LCSP.
} 
do de ejecución del contrato las normas y condiciones fijadas en el convenio colectivo de aplicación”. GALLEGO ${ }^{60}$ llama la atención sobre el relevante hecho de que, en el primero de los supuestos señalados ${ }^{61}$, la referencia a los convenios colectivos sectoriales de aplicación impide aplicar las condiciones salariales recogidas en los convenios de empresa, excluyendo de esta forma la posibilidad de aprovechar los denominados "descuelgues de convenio" previstos en el artículo 82.3 del Real Decreto Legislativo 2/2015, de 23 de octubre, por el que se aprueba el texto refundido de la Ley del Estatuto de los Trabajadores ${ }^{62}$.

\section{LA EXIGENCIA DE VINCULACIÓN ENTRE LAS CLÁUSULAS SOCIALES Y OBJETO CONTRACTUAL}

La exigencia de vinculación entre las cláusulas sociales y objeto contractual es un requisito que, como se verá en este apartado, trasciende a una concreta fase de la contratación pública, y es exigible a todas las cláusulas sociales introducidas por el órgano de contratación en cualquiera de las fases de la contratación pública, ya sea en el momento de diseñar la prestación, admitir a los candidatos, demandar una etiqueta, fijar los criterios de adjudicación o establecer condiciones especiales de ejecución del contrato.

\section{a) LA SITUACIÓN ANTERIOR A LAS DIRECTIVAS EUROPEAS SOBRE CONTRATOS PÚBLICOS DE CUARTA GENERACIÓN}

La necesidad de que las cláusulas sociales se encuentren vinculadas con el objeto contractual es reclamada por la Comisión Europea desde su Comunicación interpretativa de 2001 sobre la legislación comunitaria de contratos públicos y las posibilidades de integrar aspectos sociales en dichos $\operatorname{contratos}^{63}$. Si bien la sentencia del Tribunal de Justicia de las Comunidades Europeas de 20 de septiembre de 1988 -Beentjes- no hace mención a esta necesaria vinculación, sí lo hizo el Abogado General Darmon en sus conclusiones presentadas en este asunto, y a estas se remite la citada Comunicación ${ }^{64}$. Los primeros pronunciamientos jurisprudenciales comunitarios que reclaman la vinculación entre cláusulas cualitativas y el objeto contractual no hacían referencia a consideraciones sociales, sino medioambientales. Se trata de las sentencias del Tribunal de Justicia de las Comunidades Europeas de 17 de septiembre de 2002 -Concordia Bus Finland- y de 4 de diciembre de $2003-E V N$ AG y Wienstrom GMBH vs Republik Österreich-. Si bien estas sentencias se refieren expresamente a consideraciones medioambientales, se pueden aplicar los mismos

\footnotetext{
${ }^{60}$ Gallego (2017) p. 108.

${ }^{61}$ Igualmente, en el supuesto de que el órgano de contratación decidiese incluir en los pliegos contractuales la condición especial de ejecución prevista en el listado del artículo 202.2 párrafo tercero LCSP relativa al "cumplimiento de los convenios colectivos sectoriales y territoriales aplicables".

${ }^{62}$ El cual permite que, bajo determinadas circunstancias económicas, técnicas, organizativas o de producción, los trabajadores de una empresa puedan cobrar un salario inferior al fijado por el convenio colectivo sectorial.

63 Pp. 11, 13 y 14.

${ }^{64}$ Conclusiones presentadas el 4 de mayo de 1998, apartado $\mathrm{N}^{\circ} 35$. En el mismo sentido, las conclusiones del Abogado General Colomer, presentadas el 5 de junio de 2001, en los asuntos acumulados C-285/99 y C-286/99 (Impresa Lombardini SpA et al. vs Impresa Ing. Mantovani SpA et al.), nota No 23 al apartado № 27.
} 
principios, por analogía, a los aspectos sociales del contrato ${ }^{65}$. En ambos pronunciamientos se exige una relación directa entre las cláusulas ambientales utilizadas y el objeto del contrato, sin que aquéllos puedan hacer referencia a circunstancias ajenas a la prestación elegi$\mathrm{da}^{66}$. Esta vinculación terminará predicándose de todas las fases o circunstancias en las que se pueden incorporar aspectos sociales a la contratación pública: selección del contratista, diseño de la prestación, criterios de adjudicación del contrato y condiciones de ejecución.

Las directivas sobre contratación pública de tercera generación solamente previeron expresamente tal vinculación en relación a los aspectos sociales en sus considerandos, guardando silencio a lo largo de su articulado, que, por otra parte, únicamente tomaba en cuenta los aspectos medioambientales ${ }^{67}$. En el ordenamiento jurídico español, la Ley 30/2007, de 30 de octubre, de Contratos del Sector Público, que incorporó estas directivas al ordenamiento interno, exigió la vinculación "directa” entre las cláusulas sociales y el objeto contractual en las fases de admisión de licitadores ${ }^{68}$ y de valoración de las ofertas ${ }^{69}$. Precisamente el respeto del requisito de la vinculación entre las cláusulas sociales y el objeto de los contratos fue una de las cuestiones que mayores discrepancias ha generado en España entre el Tribunal Administrativo Central de Recursos Contractuales y sus homólogos autonómicos en supuestos como la exigencia al adjudicatario de un compromiso de aplicación de determinados convenios colectivos sectoriales a los trabajadores empleados en la ejecución del contrato; o la pretensión de que la empresa contratista contase con un plan de conciliación de la vida laboral y profesional de sus empleados ${ }^{70}$.

65 Comisión Europea (2011) p. 38, nota al pie $\mathrm{N}^{\circ} 70$.

66 La Recomendación de la Junta Consultiva de Contratación Administrativa de Madrid N 5/2001, de 27 de diciembre, sobre las cláusulas que deben incluirse en los pliegos de cláusulas administrativas y de prescripciones técnicas particulares relativas a las medidas de seguridad y salud en el trabajo, exigió que los criterios de adjudicación estuviesen vinculados "estrictamente" al objeto del contrato.

${ }^{67}$ Véase el Considerando $\mathrm{N}^{\circ} 1$ y los arts. 23.6, 44.2 párrafo segundo y 53.1 letra a) de la Directiva 2004/18/CE.

68 Artículo 51.2.

69 Artículo 134.1.

70 Así, mientras que la utilización de un criterio de adjudicación consistente en el compromiso de aplicación de determinado convenio colectivo estatal sectorial durante la vigencia del contrato fue rechazado por el Tribunal Administrativo Central de Recursos Contractuales (entre otras, por las Resoluciones $N^{\circ} 1059 / 2016$, de 16 de noviembre; 335/2017, de 21 de abril; o 553/2017, de 21 de julio), sí fue aceptado por, entre otros, el Tribunal Administrativo de Contratación Pública de Madrid (Resolución N ${ }^{\circ} 16 / 2016$, de 3 de febrero, si bien esta sería anulada posteriormente por la Sentencia del Tribunal Superior de Justicia de Madrid N 6070/2017, de 7 de junio). Respecto de los referidos planes de conciliación, fueron aceptados como criterios de adjudicación por el Tribunal Administrativo de Contratación Pública de Madrid (Resolución N 16/2016, de 3 de febrero) y el Tribunal Administrativo de Contratos Públicos de Aragón (Acuerdo N 80/2016, de 30 de agosto), pero rechazados por el Tribunal Administrativo Central de Recursos Contractuales (Resolución N 679/2017, de 27 de julio). Actualmente, la posibilidad de exigir al contratista la aplicación de medidas de conciliación de la vida laboral, personal y familiar como criterio de adjudicación del contrato está expresamente admitido por el artículo 145.2.1 ${ }^{\circ}$ LCSP. Por otro lado, la LCSP configura el respeto a las normas y condiciones fijadas en los convenios colectivos como una condición de ejecución de todos los contratos (arts. 35.1.n, 122.2, 149.4, 201 y 202.2 LCSP). 
A diferencia de sus predecesoras, las directivas de cuarta generación sí que contienen alusiones directas a la vinculación entre cláusulas sociales y objeto contractual a lo largo de su articulado. Así sucede, por ejemplo, en los artículos 43 número 1 letra a) y número 2 (etiquetas relativas a las especificaciones técnicas de la prestación), 67.3 (criterios de adjudicación del contrato) o 70 (condiciones de ejecución del contrato) de la Directiva 2014/24/UE. Esta norma supone una auténtica "revolución” en relación con sus predecesoras, al flexibilizar el vínculo entre las cláusulas sociales y el objeto contractual. La Directiva 2014/24/UE no hace sino positivizar la evolución acaecida en esta materia, pues si bien tanto la citada Comunicación interpretativa de $2001^{71}$ como la jurisprudencia inicial exigían una vinculación "directa" con el objeto del contrato $^{72}$, la jurisprudencia europea posterior flexibiliza expresamente dicha vinculación a partir de la sentencia del Tribunal de Justicia de la Unión Europea de 10 de mayo de 2012 (Comisión Europea vs Reino de los Países Bajos, asunto C-368/10 $)^{73}$. El Tribunal de Justicia advierte en este pronunciamiento ${ }^{74}$ que no es necesario que los criterios de adjudicación se refieran a características “intrínsecas" del producto, es decir, a elementos "incorporados materialmente" en este. Y ello porque las autoridades comunitarias parecen ser conscientes de que, mientras que las cláusulas ambientales inciden materialmente en las prestaciones contratadas, transformándolas y diferenciándolas del resto (así, un vehículo eléctrico es diferente de uno diésel, y un alimento ecológico es diferente de uno que no lo es) ${ }^{75}$, no ocurre así con las cláusulas sociales, excepción hecha de los supuestos de diseño universal o para todas las personas de las prestaciones contractuales ${ }^{76}$. Las cláusulas sociales no inciden directa y materialmente en el objeto contractual, puesto que la prestación en que consiste este es siempre la misma, con independencia de que se rodee o no de consideraciones de naturaleza social. Es decir,

\footnotetext{
71 Apartado 1.3.2, p. 5.

72 Así lo hace, por ejemplo, la sentencia del Tribunal de Justicia de las Comunidades Europeas de 17 de septiembre de 2002 (Concordia Bus Finland, asunto C-513/99), al exigir que los criterios de adjudicación de los contratos públicos estuviesen "estrictamente" relacionados con el objeto del contrato (apartado $\mathrm{N}^{\circ} 52$ ).

73 Si bien la sentencia del Tribunal de Justicia de la Comunidades Europeas de 4 de diciembre de 2003 (EVN AG y Wienstrom GMBH vs Republik Österreich, asunto C-448/01) ya había introducido implícitamente cierta flexibilización en esta vinculación en relación a la electricidad proveniente de fuentes de energía renovables. Véase la nota al pie siguiente.

74 Apartado $\mathrm{N}^{\circ} 91$.

75 Aunque también existen supuestos en los que las cláusulas ambientales no afectan a la sustancia material de la prestación contratada, como ocurre con la electricidad proveniente de fuentes de energía renovables, materialmente idéntica a aquélla que proviene de fuentes no renovables. Así se desprende de la sentencia del Tribunal de Justicia de la Comunidades Europeas de 4 de diciembre de 2003 (EVN AG y Wienstrom GMBH vs Republik Österreich, asunto C-448/01). Recientemente, la Resolución N 110/2018, de 18 de abril, del Tribunal Administrativo de Contratación Pública de la Comunidad de Madrid.

76 Se entiende por tales aquellos entornos, procesos, bienes, productos, servicios, objetos, instrumentos, programas, dispositivos o herramientas concebidos o proyectados desde su origen de forma que puedan ser utilizados por todas las personas, en la mayor extensión posible, incluyendo las personas con discapacidad. Véase el artículo 2 del Real Decreto Legislativo 1/2013.
} 
la obra, suministro o servicio es el mismo con independencia de que en la selección del contratista, en su proceso de producción o eliminación, en la adjudicación del contrato o en su ejecución se tengan en cuenta circunstancias sociales, pues la carretera construida, el bien suministrado o el servicio prestado son idénticos, con independencia de las condiciones sociales y laborales en el momento de su producción y comercialización, o de las circunstancias sociales y laborales de los trabajadores encargados de su ejecución (como su remuneración, condiciones de igualdad, seguridad, conciliación, comercio justo, trabajo infantil, etc.). Es decir, las cláusulas sociales no inciden sobre la naturaleza de la prestación, pues esta es la misma existan o no aquéllas.

En consonancia con lo expuesto, la Directiva 2014/24/UE considera vinculados con el objeto del contrato aquellos criterios sociales, siempre que estén referidos a cualquiera de los aspectos de las prestaciones contratadas y en cualquier etapa de su ciclo de vida, incluidos aquellos factores que intervengan en el proceso específico de producción, preparación o comercialización, o en un proceso específico de otra etapa de su ciclo de vida, incluso cuando tales factores no formen parte de su "sustancia material" materialmente en la prestación contratada.

Como no podía ser de otro modo, la LCSP recoge esta previsión en su articulado en relación a todas las fases de la contratación ${ }^{78}$. Sin embargo, la flexibilización del vínculo entre los criterios sociales y el objeto contractual no implica de ningún modo la eliminación de dicho vínculo, de forma que aquéllos puedan afectar a cualquier circunstancia relacionada, siquiera tangencialmente, con la prestación. La vinculación con el objeto del contrato no exige que la prestación varíe su naturaleza material por incluir consideraciones sociales, pero sí que aquellos elementos sobre los que recaigan las cláusulas sociales realmente afecten a la ejecución de las prestaciones contratadas en cualquiera de las fases de su ciclo de vida (extracción de materias primas, investigación y desarrollo, fabricación o producción, comercialización, transporte, utilización, mantenimiento, eliminación, etc. $)^{79}$. Así, resultan admisibles las cláusulas sociales que recaen sobre los trabajadores que ejecutan materialmente la prestación, pero no aquellas que afecten, por ejemplo, al consejo de administración de la empresa contratista (al no participar en su ejecución material) ${ }^{80}$. Precisamente esta necesidad de que las cláusulas sociales afecten a los trabajadores vinculados -en una u otra fase- con la ejecución de la prestación contractual es la razón por la cual la Directiva 2014/24/UE no admite la existencia de dicho vínculo en relación a los criterios y condiciones relativos a la política general de responsabilidad corporativa de las empresas contratistas, pues "[...] no puede considerarse como un factor que caracterice el proceso específico de producción o prestación de las obras, suministros o servicios adquiridos”, y, en consecuencia, "[...] los poderes adjudicadores no pueden estar autorizados a exigir a

\footnotetext{
77 Artículos 42.1 párrafo segundo, 67.3 y 70 de la Directiva 2014/24/UE.

78 Admisión de licitadores (art. 74.2), establecimiento de prescripciones técnicas (art. 126.2), uso de etiquetas (art. 127.2.a), criterios de adjudicación (art. 145.5), criterios de desempate (art. 147) y condiciones especiales de ejecución del contrato (art. 202).

79 O, dicho en otras palabras, que "contribuyan” a la realización de las prestaciones pactadas. Gimeno (2010) p. 237.

80 Tampoco sería admisible, por ejemplo, por carecer de vinculación con el objeto del contrato, una cláusula social que exigiese la paridad entre hombres y mujeres en el consejo de administración de una empresa.
} 
los licitadores que tengan establecida una determinada política de responsabilidad social o medioambiental de la empresa" ${ }^{\prime 1}$.

\section{REFLEXIÓN FINAL. EQUILIBRIO ENTRE MERCADO Y TUTELA DE LOS DERECHOS SOCIALES Y LABORALES: UNA NECESARIA RECONSIDERACIÓN DEL CONTENIDO DEL PRINCIPIO DE EFICIENCIA EN EL GASTO PÚBLICO}

La posición que la Unión Europea ha mantenido durante los últimos años en lo relativo al uso de la contratación pública como un instrumento de la política social comunitaria puede explicarse si se analiza desde la perspectiva de los dos elementos que componen la denominada Economía Social de Mercado: libre iniciativa económica en combinación con un elevado progreso social, en el sentido consagrado por el artículo 3.3 TUE. Las instituciones que componen la Unión Europea han tratado de mantener un equilibrio entre ambos factores, si bien, como ha habido ocasión de comprobar, su posición ha pivotado durante los últimos años desde una inicial desconfianza hacia el uso de cláusulas sociales en la contratación pública - muy especialmente, en lo relativo a la admisibilidad de criterios sociales de adjudicación de los contratos-, a su admisión generalizada, si bien supeditada a ciertos requisitos de creación jurisprudencial positivizados por el Derecho derivado. La razón de tal reticencia a la admisión de cláusulas sociales en la contratación pública debe encontrarse en el entendimiento, por parte de las instituciones comunitarias, de que la libre concurrencia de empresas en el Mercado Único Europeo se garantiza cuando la contratación pública se desarrolla a partir de criterios de naturaleza económica, esto es, relativos a realidades mensurables cuantitativamente. Como ha señalado GonZÁLEZ ${ }^{82}$, la aceptación de cláusulas de sostenibilidad en los contratos públicos ha estado condicionada por su impacto en el Derecho comunitario, posiblemente por los riesgos que, por parte de algunos, se intuían sobre el mercado interior. En este sentido, se consideró que la competencia entre empresas, motor indubitado del progreso económico de una sociedad, podía quedar debilitada si las decisiones de compra de los poderes públicos marginaban los aspectos económicos del contrato en favor de circunstancias no evaluables monetariamente, como la sostenibilidad ambiental o social.

Dos han sido los mecanismos que han utilizado las instituciones comunitarias para tratar de garantizar la competencia entre empresas en el marco del Mercado Único Europeo. En primer lugar, la obligación de que las cláusulas sociales se encuentren vinculadas con el objeto del contrato en todas las fases de la contratación pública. En segundo lugar, que la aplicación de consideraciones sociales respete en todo caso el principio de no discriminación entre licitadores de los diferentes Estados miembros ${ }^{83}$. Como se ha expuesto, en virtud del primero de estos mecanismos, únicamente serán admisibles aquellas cláusulas sociales vinculadas con la prestación objeto del contrato, por afectar a los trabajadores en-

\footnotetext{
${ }^{81}$ Considerando $\mathrm{N}^{\circ} 97$ párrafo segundo.

82 González García (2015) p. 22.

${ }^{83}$ Recogido, por ejemplo, en los artículos 132, 145.5.b), 148.3.a) o 202.1 LCSP.
} 
cargados de ejecutar la prestación en cualquiera de las fases de su ciclo de vida. Las instituciones comunitarias entendieron que tales cláusulas sociales solamente estaban justificadas en aras de la política social europea si se referían al objeto del contrato en cuestión, pero en ningún caso si afectaban a circunstancias generales de los operadores económicos ajenas a la prestación contractual, como, por ejemplo, las condiciones laborales de trabajadores no relacionados con la ejecución del contrato (trabajadores que realicen otras funciones o cuadros directivos) o la política general de una empresa (responsabilidad social corporativa).

Ambos mecanismos constituyen limitaciones al uso de consideraciones sociales en la contratación pública justificadas por la necesidad de salvaguardar la integridad del Mercado Único. Pero, mientras que el respeto al principio de no discriminación entre licitadores no ha sufrido cambios sustanciales a lo largo del tiempo respecto de su tratamiento jurisprudencial o normativo, la exigencia de vinculación entre las cláusulas sociales y el objeto del contrato ha experimentado, como se ha podido comprobar, un proceso de flexibilización con el objetivo de admitir un mayor número de cláusulas de sostenibilidad contractual, fundamentalmente en materia social. En cualquier caso, y como se ha expuesto también, de ninguna forma se habría producido una ruptura o eliminación del nexo entre cláusulas sociales y objeto contractual, pues este debe existir, en los términos expuestos, para que aquéllas resulten admisibles en virtud del Derecho comunitario. La pervivencia de este vínculo encuentra su justificación, en última instancia, en la búsqueda, por parte del legislador europeo, de un equilibrio entre las políticas sociales comunitarias y la libre competencia en el marco del Mercado Único Europeo.

Resulta igualmente necesario reflexionar sobre los principios que han inspirado tradicionalmente la contratación pública para identificar las razones que han llevado al legislador europeo a apostar decididamente por la contratación pública social. Al adjudicar el contrato a la oferta económicamente más ventajosa los poderes públicos han perseguido, en última instancia, alcanzar la eficiencia en la compra pública. Pero la entrada de otros factores de naturaleza no económica, como las características estéticas o funcionales, o las mismas consideraciones sociales, han matizado este principio en favor de otros principios y políticas comunitarias, como las relacionadas con la sostenibilidad. A pesar de ello, y durante un tiempo, los criterios económicos, como el precio del contrato, mantuvieron un status privilegiado como elemento determinante de su valor económico, en el sentido de admitirse la adjudicación de un contrato teniendo en cuenta, como único criterio de selección de las ofertas, su precio. La norma española iba incluso un paso más allá, al exigir tradicionalmente que en el supuesto de que el órgano de contratación eligiese un único criterio de adjudicación, este debía ser, necesariamente, el precio más bajo.

Las directivas de cuarta generación han abierto las puertas al destierro definitivo del precio como factor determinante para la selección de la oferta económicamente más ventajosa. Y ello porque, tanto si se opta por un planteamiento basado en la mejor relación calidad-precio, como si se hace en favor de la mejor relación coste-eficacia, resulta posible adjudicar el contrato sin tener en cuenta el precio de las ofertas, sino atendiendo únicamente a su sostenibilidad ambiental o social. En primer lugar, y como se ha expuesto al analizar esta cuestión en la nueva regulación contenida en la LCSP, la mejor relación calidad-precio puede evaluarse con arreglo a criterios cualitativos como las características sociales del con- 
trato, y aunque estos criterios deben ir siempre acompañados de un criterio relacionado con los costes, este no tiene por qué ser necesariamente el precio, siendo suficiente con que se trate de una planteamiento basado en la rentabilidad, como el coste del ciclo de vida, en el que tienen cabida cuestiones sociales y laborales. En segundo lugar, la mejor relación coste-eficacia permite igualmente desatender el precio de las ofertas y optar por su coste, entrando de nuevo en juego el coste del ciclo de vida de la prestación. Pero esto no es todo, pues el legislador español ha eliminado la señalada regla que exigía que en caso de que el órgano de contratación estableciese un único criterio de adjudicación este fuese el precio más bajo. Ahora el criterio único de contratación deberá estar relacionado necesariamente con los costes del contrato, pudiendo ser el precio o, una vez más, un criterio basado en la rentabilidad, como el coste del ciclo de vida. Además, el legislador español prohíbe que el precio sea el único factor determinante de la adjudicación en varios supuestos, entre los que se encuentran los contratos de servicios sociales cuando estos fomenten la integración de personas desfavorecidas o de miembros de grupos vulnerables. En este último supuesto, si bien no se excluye el criterio del precio más bajo, sí que se compensa obligatoriamente con otros criterios de adjudicación.

A pesar de este evidente cambio de paradigma en la contratación pública, no puede entenderse de ninguna forma que el legislador comunitario haya renunciado al principio del uso eficiente de los fondos destinados a la contratación pública, el cual sigue estando muy presente en todo el texto de las directivas de cuarta generación y de la nueva LCSP. Simplemente se ha reconfigurado el principio de eficiencia del gasto público en este ámbito, modificando su contenido, el cual evoluciona desde la tradicional eficiencia económica a la nueva eficiencia "social", en el convencimiento, por parte de las autoridades comunitarias, de que el uso de criterios de sostenibilidad social en la contratación pública contribuye a una mayor eficiencia en la utilización de los fondos públicos, pues los mayores costes asociados a la contratación socialmente responsable serán compensados por los ahorros generados en políticas sociales. En otras palabras, que los ahorros sociales generados por estas políticas serán, como mínimo, iguales a los eventuales incrementos en el coste de contratar prestaciones socialmente sostenibles. Así lo reconoce el propio legislador español en el artículo 1.3 LCSP al exigir la incorporación transversal y preceptiva de criterios sociales en la contratación pública "[...] en la convicción de que su inclusión proporciona una mejor relación calidad-precio en la prestación contractual, así como una mayor y mejor eficiencia en la utilización de fondos públicos”. Esta sería la razón por la cual las actuales directivas de contratos incluyen entre los principios de la contratación pública el cumplimiento de las normas aplicables en materia medioambiental, social y laboral junto con los tradicionales principios igualdad de trato, no discriminación, transparencia y proporcionalidad. Sin entrar a valorar si existe o no constatación empírica de los pretendidos ahorros económicos generados por la contratación pública socialmente sostenible ${ }^{84}$, lo cierto es que la incorporación de este nuevo dogma a los ordenamientos jurídicos europeo y español es un hecho tras la entrada en vigor de las directivas sobre contratos públicos de cuarta generación y de la LCSP, tal y como se ha pretendido poner de manifiesto a lo largo de este trabajo.

${ }^{84}$ Véase, por todos, Saussier y Tirole (2015) pp. 1-12. 


\section{BIBLIOGRAFÍA CITADA}

Andrés Pérez, María del Rocío (2016): “El coste económico de no incluir cláusulas sociales en la contratación”. Disponible en: http:/www.obcp.es/index.php/mod.opiniones/ mem.detalle/id.246/relcategoria.208/relmenu.3/chk.58b948e3dd6f6ab8a6cde982331f4 4e1. Fecha de consulta: 12 de octubre de 2017.

Arrowsmith, Susan (2002): “The EC Procurement Directives, National Procurement Policies and Better Governance: The Case for A New Approach", European Law Review, $\mathrm{N}^{\circ}$ 1: pp. 3-24.

Aymerich Cano, Carlos y Ferreira Fernández, Antonio Javier (2014): "El tratamiento de las cláusulas sociales en la normativa reguladora de la contratación pública. En particular las cláusulas sociales como criterio de adjudicación de los contratos”, en RoDRíGUEZArana Muñoz, Jaime y Jinesta Lobo, Ernesto (dirs.), El Derecho administrativo en perspectiva. Homenaje al profesor Dr. José Luis Meilán Gil, Tomo II, (Madrid, Ediciones RAP) pp. 33-51.

Comisión Europea (1989): Comunicación de 22 de septiembre de 1989 "Aspectos regionales y sociales de la contratación pública", COM (89) 400 final, Bruselas, DOCE No C 311, de 12 de diciembre de 1989.

Comisión Europea (1998): Comunicación de la Comisión Europea de 11 de marzo de 1998 "La contratación pública en la Unión Europea", COM (98) 143, Bruselas, 11 de marzo de 1998.

Comisión Europea (2001): Comunicación interpretativa de 15 de octubre de 2001, sobre la legislación comunitaria de contratos públicos y las posibilidades de integrar aspectos sociales en dichos contratos, (2001/C 333/08), Bruselas, DOUE No 333, de 28 de noviembre de 2001, COM (2001) 566 final, pp. 0027 a 0041. Disponible en: https:/leur-lex.europa.eul legal-content/ES/TXT/?uri=CELEX\%3A52001DC0566. Fecha de consulta: 20 de junio de 2019.

Comisión Europea (2011): Adquisiciones sociales. Una guía para considerar aspectos sociales en las contrataciones públicas.

Comisión Europea (2017): Documento de reflexión sobre la dimensión social de Europa, Bruselas, 26 de abril de 2017, COM (2017) 206.

Estorninho, Maria João (2014): "La Estrategia Europa 2020 y las consideraciones sociales y ambientales en la adjudicación de contratos públicos”, en Balaguer Callejón, F. y Arana García, Estanislao (coords.), Libro homenaje al profesor Rafael Barranco Vela, (Madrid, Thomson Reuters-Civitas) pp. 2749-2758.

Gallego Córcoles, Isabel (2011): “Cláusulas sociales, contratación pública y jurisprudencia del TJUE”, Contratación administrativa práctica, No 113: pp. 64-69.

Gallego Córcoles, Isabel (2017): "La integración de cláusulas sociales, ambientales y de innovación en la contratación pública”, Documentación Administrativa, nueva época, $\mathrm{N}^{\circ}$ 4, enero-diciembre: pp. 92-113.

Gimeno Feliú, José María (2010): Novedades de la Ley de Contratos del Sector Público de 30 de octubre de 2007 en la regulación de la adjudicación de contratos públicos (Madrid, Civitas). 
Gosálbez Pequeño, Humberto (2003): “¿Cláusulas sociales en la selección de los contratistas de las Administraciones públicas españolas?”, Justicia Administrativa. Revista de Derecho Administrativo, No 20, julio: pp. 27-67.

Medina ArnÁiz, Teresa (2012): "La contratación pública socialmente responsable a través de la jurisprudencia del Tribunal de Justicia de la Unión Europea”, Revista Española de Derecho Administrativo, No 153: pp. 213-214.

Miranda Boto, José María (2016): "Contratación pública y cláusulas de empleo y condiciones de trabajo en el Derecho de la Unión Europea”, Lex Social. Revista jurídica de los Derechos Sociales, Vol. 6, No 2, julio-diciembre: pp. 69-91.

Müller-Armack, Alfred. (1962): "Estudios sobre la economía social de mercado", Revista de economía y estadistica, Vol. 6, N 4, 40 trimestre: pp. 173-221.

RazQuin Lizárraga, Martín María, y Vázquez Matilla, Francisco Javier (2017): La adjudicación de contratos públicos en la nueva Ley de Contratos del Sector Público (Cizur Menor, Thomson Reuters-Aranzadi).

Romeo Ruiz, Aritz (2017): “Contratación pública social y derecho de la Unión Europea”, en RazQuin Lizárraga, Martín María y Alenza García, José Francisco (coords.) et al., La nueva contratación pública: mercado y medio ambiente, (Cizur Menor, Thomson Reuters-Aranzadi) pp. 405-422.

Santías Viada, José Antonio (2001): "Modificaciones introducidas en el texto de la Ley de Contratos de las Administraciones Públicas, en materia de procedimientos, formas y criterios de adjudicación de los contratos", Noticias de la Unión Europea, $\mathrm{N}^{\circ} 198$ : pp. 71-82.

Saussier, Stéphane y Tirole, Jean (2015): "Renforcer l'efficacité de la commande publique", Notes du conseil d'analyse économique 2015/3, N²2: pp. 1-12.

Sols Lucía, José, Florensa Giménez, Albert y Camprodón Rosanas, Marta (2009): "Medio siglo de economía social de mercado", Revista de fomento social, No 253: pp. 79-102.

VázQuez Matilla, Francisco Javier (2017): "Novedad! Comisión Europea: nuevas estrategias para la contratación estratégica". Disponible en http://www.javiervazquezmatilla. com/2017/10/contratacionestrategica/. Fecha de consulta: 12 de mayo de 2018.

\section{NORMAS CITADAS}

\section{UNIÓN EUROPEA:}

Directiva 71/305/CEE, de 26 de julio, sobre coordinación de los procedimientos de adjudicación de los contratos públicos de obras.

Directiva 92/50/CEE, de 18 de junio, sobre coordinación de los procedimientos de adjudicación de los contratos públicos de servicios.

Directiva 93/36/CEE, de 14 de junio, sobre coordinación de los procedimientos de adjudicación de los contratos públicos de obras.

Directiva 93/37/CEE, de 14 de junio, sobre coordinación de los procedimientos de adjudicación de los contratos públicos de obras.

Directiva 96/71/CE, de 16 de diciembre, sobre desplazamiento de trabajadores efectuados en el marco de una prestación de servicios. 
Directiva 2004/17/CE, de 31 de marzo, sobre la coordinación de los procedimientos de adjudicación de contratos en los sectores del agua, de la energía, de los transportes y de los servicios postales.

Directiva 2004/18/CE, de 31 de marzo, sobre coordinación de los procedimientos de adjudicación de los contratos públicos de obras, de suministro y de servicios.

DiRECTIVA 2014/23/UE, de 26 de febrero, relativa a la adjudicación de contratos de concesión.

Directiva 2014/24/UE, de 26 de febrero, sobre contratación pública y por la que se deroga la Directiva 2014/18/CE.

Directiva 2014/25/UE, de 26 de febrero, relativa a la contratación por entidades que operan en los sectores del agua, la energía, los transportes y los servicios postales y por la que se deroga la Directiva 2004/17/CE.

\section{ESPAÑA:}

Ley 30/2007, de 30 de octubre, de Contratos del Sector Público.

Real Decreto Legislativo 3/2011, de 14 de noviembre, por el que se aprueba el texto refundido de la Ley de Contratos del Sector Público.

Real Decreto Legislativo 1/2013, de 29 de noviembre, por el que se aprueba el Texto Refundido de la Ley General de derechos de las personas con discapacidad y de su inclusión social.

Real Decreto Legislativo 2/2015, de 23 de octubre, por el que se aprueba el texto refundido de la Ley del Estatuto de los Trabajadores.

LEY 9/2017, de 8 de noviembre, de Contratos del Sector público.

\section{JURISPRUDENCIA CITADA}

Sentencia del Tribunal de Justicia de las Comunidades Europeas de 20 de septiembre de 1988 (Gebroeders Beentjes vs Reino de los Paises Bajos, asunto 31/87).

Sentencia del Tribunal de Justicia de las Comunidades Europeas de 26 de diciembre de 2000 (Comisión vs Francia Nord-Pas-de-Calais, asunto C-225/98).

Sentencia del Tribunal de Justicia de las Comunidades Europeas de 18 de octubre de 2001 (SIAC Construction Ltd vs County Council of the County of Mayo, asunto C-19/00).

Sentencia del Tribunal de Justicia de las Comunidades Europeas de 17 de septiembre de 2002 (Concordia Bus Finland Oy Ab vs Helsingin Kaupunki et al., asunto C-513/99).

Sentencia del Tribunal de Justicia de la Comunidades Europeas de 4 de diciembre de 2003 (EVN AG y Wienstrom GMBH vs Republik Österreich, asunto C-448/01).

Sentencia del Tribunal de Justicia de las Comunidades Europeas de 7 de octubre de 2004 (Sintesi SpA vs Autorità per la Vigilanza sui Lavori Pubblici, asunto C-247/02).

Sentencia del Tribunal de Justicia de las Comunidades Europeas de 27 de octubre de 2005 (Contse SA, Vivisol Srl y Oxigen Salud SA vs Instituto Nacional de Gestión Sanitaria (Ingesa), asunto C-234/03).

Sentencia del Tribunal de Justicia de las Comunidades Europeas de 11 de diciembre de 2007 (International Transport Workers' Federation et al. vs Viking Line ABP et al., asunto C-438/05). 
RomÁn MÁrquez, Alejandro "Tutela y promoción de los derechos sociales y laborales por las directivas europeas..."

Sentencia del Tribunal de Justicia de las Comunidades Europeas de 18 de diciembre de 2007 (Laval un Partneri Ltd. vs Svenska Byggnadsarbetareförbundet et al., asunto C-341/05).

Sentencia del Tribunal de Justicia de las Comunidades Europeas de 3 de abril de 2008 (Dirk Rüffert vs Land Niedersachsen, asunto C-346/06).

Sentencia del Tribunal de Justicia de la Unión Europea de 17 de noviembre de 2015 (RegioPost GmbH \& Co. KG vs Stadt Landau in der Pfalz, asunto C-115/14).

España: Sentencia del Tribunal Superior de Justicia de Madrid Nº 6070/2017, de 7 de junio. 